\title{
Multi-Criteria Inventory Optimisation of University of Ibadan, Ibadan, Nigeria's Bakery Using Goal Programming Approach and Flour as the Major Raw-Material
}

\author{
*Bolarinwa, Mojisola A. ${ }^{1}$, Fajebe, Fisayo E. ${ }^{2}$ \\ ${ }^{1,2}$ Department of Industrial and Production Engineering, University of Ibadan, Ibadan, Nigeria
}

\begin{abstract}
Asides inventory cost, which is being used as the only inventory performance measure at the University of Ibadan bakery, a number of other criteria, such as inventory cost, service level, inventory turnover and delivery lead time which influence the performance of an inventory system have surfaced over the years. Hence, there is the need to examine all these criteria-objectives altogether. Therefore, this research was centred towards optimising the inventory system of University of Ibadan bakery, putting multiple criteria into consideration. Data on 17 raw materials: their costs, suppliers, usage rate, lead time, storage space and available capital were collected by means of interviews, past records and observations. The weighted goal program algorithm was adopted to find the best compromise between fulfilling the four objectives by minimising the sum of the deviation from the target values of the goals. Subsequently, Lingo 17.0 and Tora 1.0 optimisation software packages were used to solve and compare the model generated, while putting into consideration storage space constraint and budgeted capital. The developed model from the goal programming algorithm exhibited four goals (combined into one objective function). Same solutions were obtained from Lingo 17.0 and Tora 1.0. While Lingo 17.0 gave a uniform service level of $100 \%$, a turnover ratio greater than $1(>1)$ for all the materials at a negligible increase (of $<0.0001 \%$ ) in total inventory cost of the raw materials and available lead time duration of zero days $(<24$ hours) for each material, Tora 1.0 gave a uniform service level of $100 \%$, a turnover ratio greater than $1(>1)$ for all the materials at a negligible increase (of $<0.0001 \%$ ) in total inventory cost of the raw materials and available lead time duration of zero days ( $<24$ hours) for each material. Implementation of the developed model will eliminate unnecessary waiting time between production, thereby ensuring effective and efficient utilisation of raw materials in production which will lead to reduced cost of holding inventory, elimination of unnecessary overall cost and wastages, and also improvement of the productivity and profit on the long run.
\end{abstract}

Keywords: Inventory system, multi-criteria optimisation, goal programming, productivity, bakery

\section{Introduction}

In a bid to meet present and future requirements, every organisation needs a set of resources with economic value, referred to as Inventory [8], [12], [15]. In most firms across the globe, inventory serves as the major revenue provider, asides service-based organisations which carry little or no inventory. Hence, inventory consists of all forms of investment of an organisation from which return is expected [20], [13], [3]. For an organisation to pull through the current downtime in the Nigerian economy and also attain competitive superiority in the swiftly evolving environment and in the global market, it is crucial for a firm to keep inventory for raw materials, finished product or any other form of item at the right time and right level of quality by striking a balance between fulfilling the inventory management objectives or finding a trade-off [23], [10]. Hence, Inventory management is a vital factor for competitive advantage and operational performance particularly in inventory intensive manufacturing industries [18], [23], [3]. Inventory management requires a planning process that employs methods and tools to allow firms plan inventory targets of right product, right place and right time; which aid in mitigating the impacts of shortages in 
supply, unpredictable demand, and lead times, while improving inventory flow and keeping inventory cost minimal [9], [14]. This planning process is called Inventory optimisation. The optimisation process involves choosing the best resource options that best satisfies the objective function(s) of the mathematical model formulated for inventory problem. Effective and efficient revenue generation is pertinent for the survival of an organisation, hence, one cannot afford to underestimate the need to optimise the inventory system. Inventory models with single objectives mostly seek to obtain the least total cost and this is commonly solved through the application of linear programming models ([19], [4]. The utilisation of linear programming models in making inventory planning decisions has been a prevalent practice in literature, where the objective function is usually formulated as a single objective expressed in terms of the quantity of items to buy or produce at the least cost possible. This expression usually comprises of inventory carrying, ordering and shortage costs, as well as unit production and distribution costs [5], [1]. However, according to recent studies in planning inventory and distribution, the modelling of real-life inventory optimisation problems requires more than only an objective of minimum cost [11], [25], [7]. Other objectives might include maximisation of inventory service level, minimisation of total inventory lead time, minimisation of inventory level, maximisation of environmental impact, maximisation of inventory turnover ratio, etc. Since fulfilling these set of objectives individually can be controversial and inconclusive at times, there is thus a need to apply more advanced programming models; multi-criteria optimisation models. Multi-criteria optimisation models have been established due to the observation that real life problems necessitate being solved optimally with respect to the overall different categories of criteria that influence them. They also inhibit ideal solution [6], [2]. In unravelling multi-objective problems, the major task is finding the optimal level of all the criteria sufficient to make suitable decisions [26]. There are numerous techniques utilised in solving multi-objective problems. These methods include; compromise programming, goal programming, weighted sum scalarisation, compromise constraints bi-objective linear programming etc. In this study, goal programming was used. Goal programming is a classic multi-objective optimisation method and an augmentation of linear programming implemented in solving various multi-criteria problem scenarios subject to some specified goal constraints [22], [17]. The approach is to minimise the absolute sum of deviation of objectives from their predefined set of targets in order of priority [21], [16]. The University of Ibadan bakery inventory items are usually re-ordered weekly. However, this weekly order ought not to be the limit. Therefore, this study was centred towards investigating the benefit(s) of monthly order, so as to take advantage of discount and bulk order. Moreover, the current system does not have an adequate approach to optimising the inventory system components, as only cost is considered. Hence, there is the need to broaden the horizon of appraisal of the University of Ibadan's bakery inventory performance to optimise simultaneously the following additional objectives; inventory service level, lead time and inventory turnover rate, as well as the constraint on the storage capacity of each inventory item. The use of quantitative mathematical programming as a scientific approach to inventory system problems already exists in literature, but the University of Ibadan's bakery inventory system problem requires concurrent consideration of the increasing number of factors that influence the inventory system by employing the multi-objective optimisation technique; goal programming, to achieve the best compromise between these objectives. Thus, the aim of this work was to optimise a multi-criteria inventory system for University of Ibadan's bakery using goal programming approach in solving the problem(s) therein. Then, the objectives of this work include: (1) Studying the inventory system of the bakery (2) Developing a multi-criteria optimisation model using goal programming and (3) Solving the developed model using two optimisation software packages (Lingo 17.0 and Tora 1.0) for comparison and selecting the best compromise solution, given the existing conditions. Justification included the fact that multi-criteria optimisation allows consideration of several other objectives of the Inventory system of University of Ibadan bakery or goals associated with the bakery simultaneously (not only the inventory cost), and helps prioritise these objectives either pre-emptively or non-pre-emptively.

\section{Methodology}

\subsection{Setting}

The University of Ibadan, Ibadan bakery was selected and severally visited for the collection of necessary information and data. 


\subsection{Data Collection}

The data was collected from the University's bakery by means of:

1. Interview of Personnel: These include the store keeper, chief baker, bakery manager and the accountant.

2. Records Checking: Existing records of 17 raw materials for the period of three (3) years (2016 2018) were checked out, with relevant information gathered from there.

3. Bakery site inspection: The bakery was understudied for a period of two (2) weeks in order to monitor the reorder rate and the storage capacity available for each raw material.

\subsubsection{Coverage area of data collected}

1. Bill of Materials (BOM): Contained information on all raw materials used in the bakery.

2. List of Suppliers: Contained the reliable suppliers of each product.

3. List of Products: Contained the different types of bread coming from UI bakery.

4. Inventory costs: Estimated cost of (i) sending enquiries (ii) transports (iii) inspection (iv) clearing costs (v) others, such as telephone charges. Herein, the ordering cost was also obtained.

5. Usage requirements: Obtained from the records of the chief baker and store-keeper, as well as the estimated need of each production's input materials obtained from of the raw materials room (with information on consumption rate/materials replenishment).

6. Storage capacity: Maximum space obtainable in the bakery for the storage of each raw material and obtained from personal observation and interaction with the store-keeper.

7. Delivery lead time: Varies with raw materials and corresponding suppliers, and obtained from personal observation and existing records with the store-keeper.

8. Capital available: Monetary value of each available raw material obtained from the accountant.

\subsubsection{Steps taken to guide the use of non-pre-emptive goal programming approach}

1. Priority level of each goal was decided.

2. The goals were ranked so that weights were attached to them.

3. The decision variables were defined.

4. The deviational variables for each goal was defined.

5. Constraints which include goal and technology were formulated.

6. Objective function was formulated.

7. The resulting goal program was solved using Lingo 17.0 and Tora 1.0 software packages.

8. The evolving solution was interpreted for implementation.

\subsection{Model assumptions}

1. The purchase price of each material remains constant.

2. The cost of ordering is known and fixed.

3. Lead times are known and constant

4. Production requirement rate for each material is known and constant

5. Shortages are not allowed.

6. Holding costs are known and fixed, might be different for each raw material.

7. There is a storage space constraint on the raw materials.

Basic notations and terms include:

1. $C_{k}=$ Cost of a single item of material "k".

2. $Y_{k t}=$ decision variable for number of units of material " $\mathrm{k}$ " to order in period " $\mathrm{t}$ ".

3. $Z_{k t}=$ binary decision variable for order period of material "k". It is used in "taking "yes/no" decisions; in this case the decision of whether or not to order for a specific material " $\mathrm{k}$ " in a period " $t$ '.

4. $S_{k t}=$ fixed order cost for a unit of material " $\mathrm{k}$ " in period " $\mathrm{t}$ ".

5. $h_{k}=$ holding cost of a unit of material "k".

6. $\pi_{k}=$ shortage cost for a unit of material " $\mathrm{k}$ ". 
7. $C_{t}^{0}=$ Represents the monetary resource allocation at a period of concern. It is given as the total budget for the purchase of these materials.

8. $\mathrm{T}=$ number of periods in planning horizon.

9. $\mathrm{m}=$ number of materials.

10. $I_{k t}=$ decision variable for inventory position of material " $\mathrm{k}$ " at period " $\mathrm{t}$ ".

11. $I_{k t}^{+}=$total number of materials actually in inventory. Demand plus buffer stock.

12. $I_{k t}^{-}=$total number of backorders or shortage.

13. $D_{k t}=$ usage requirement for production of material " $\mathrm{k}$ " in period " $\mathrm{t}$ ".

14. $L_{k t}=$ Minimum service level (subjectively determined by the decision maker).

15. $T_{r}=$ desirable inventory turnover rate.

16. $M_{k}=$ maximum capacity of material " $\mathrm{k}$ " that can be ordered in period " $\mathrm{t}$ ".

17. $A_{k}=$ Available lead time to order material "k".

18. $A_{k}^{\prime}=$ time material " $\mathrm{k}$ " is received.

19. $A_{k}^{\prime \prime}=$ time material ' $\mathrm{k}$ " is ordered.

20. $d_{1}^{+}$and $d_{1}^{-}=$the overachievement and underachievement in relation to the specific goal value. It can also be referred to as the positive and negative deviations from the target value of the goal.

\subsection{Ranking of goals}

Since the achievement of each of the goals is of relative importance in inventory optimisation decision making, the weighted goal programming approach was utilized using the following weights selections:

$$
\begin{aligned}
& \mathrm{W}_{1}=\text { weight for inventory cost minimisation } \\
& \mathrm{W}_{2}=\text { weight for inventory service level maximisation } \\
& \mathrm{W}_{3}=\text { weight for inventory turnover ratio maximisation } \\
& \mathrm{W}_{4}=\text { weight for inventory lead time minimisation }
\end{aligned}
$$

\subsubsection{Objective function}

The corresponding slacks/surpluses were thus added depending on minimisation/maximisation factor and the objective function is therefore given as:

$$
\text { Minimize } \mathrm{Z}=W_{1} d_{1}^{+}+W_{2} d_{2}^{-}+W_{3} d_{3}^{-}+W_{4} d_{4}^{+}
$$

\subsubsection{Model constraints}

This consists of all the constraints in the model formulation spanning from the goal constraints to the economic or hard constraints. It also includes the binary variable constraint and non-negativity constraints,

\subsubsection{Goal constraints}

1. Minimisation of the total inventory cost: This is the sum of the inventory ordering, holding and shortage costs. It is expressed as:

$$
\begin{aligned}
\sum_{k=1}^{m} \sum_{t=1}^{T}\left\{\left(C_{k} Y_{k t}+Z_{k t} S_{k t}\right)+h_{k}\left(\frac{I_{k t}^{+}+I_{k, t-1}^{+}}{2}\right)+\pi_{k}\left(\frac{I_{k t}^{-}+I_{k, t-1}^{-}}{2}\right)\right\} \leq C_{t}^{0} \\
\sum_{k=1}^{m} \sum_{t=1}^{T}\left\{\left(C_{k} Y_{k t}+Z_{k t} S_{k t}\right)+h_{k}\left(\frac{I_{k t}^{+}+I_{k, t-1}^{+}}{2}\right)+\pi_{k}\left(\frac{I_{k t}^{-}+I_{k, t-1}^{-}}{2}\right)\right\}+d_{1}^{-}-d_{1}^{+}=C_{t}^{0}
\end{aligned}
$$

2. Maximisation of the service level of the firm: This is measured by the type 2 service level also known as inventory fill rate.

$$
\begin{gathered}
\text { Fill rate }=1-\left(\frac{\text { numberofbackorders }}{\text { totaldemand }}\right) \\
{\left[1-\left(\frac{I_{k t}^{-}}{\sum_{k}^{m} D_{k t}}\right)\right] \geq L_{k t}} \\
{\left[1-\left(\frac{I_{k t}^{-}}{\sum_{k}^{m} D_{k t}}\right)\right]+d_{2}^{-}-d_{2}^{+}=L_{k t}}
\end{gathered}
$$


3. Maximisation of the inventory turnover rate (ITR): Inventory turnover is a measure of how efficiently a company can control its merchandise, so it is important to have a high turnover rate.

$$
\begin{gathered}
\text { ITR }=\frac{\text { costof goodssold }}{\text { Averageinventory }}=\frac{\text { costofgoodssold }}{(\text { beginninginventory+endinginventory }) / 2} \\
\sum_{k=1}^{m} \sum_{t=1}^{T}\left\{\frac{C_{k} D_{k t}}{\sum_{k=1}^{m} C_{k}\left[\frac{\left.I_{k 0}^{+}+I_{k T}^{+}\right]}{2}\right]}\right\} \geq \operatorname{Tr} \quad \text { (2.6) } \\
\sum_{k=1}^{m} \sum_{t=1}^{T}\left\{\frac{C_{k} D_{k t}}{\sum_{k=1}^{m} C_{k}\left[\frac{I_{k 0}^{+}+I_{k T}^{+}}{2}\right]}\right\}+d_{3}^{-}-d_{3}^{+}=\operatorname{Tr}
\end{gathered}
$$

4. Minimisation of lead time: Lead time is receiving Time - order time

$$
=A_{K}^{\prime}-A_{K}^{\prime \prime} \leq A_{k} \quad A_{K}^{\prime}-A_{K}^{\prime \prime}+d_{4}^{-}-d_{4}^{+}=A_{k}
$$

\subsubsection{Technological or hard constraints}

1. Inventory balance constraints: The optimal inventory position at a particular period must be equal to the ending inventory position of the previous period plus the number of products ordered minus the total demand for the products for that period. Also, the total amount of products kept in inventory must be equal to the optimal inventory level plus the number of backorders. Given as:

$$
\begin{aligned}
I_{k t} & =I_{k, t-1}+Y_{k t}-\sum_{k}^{m} D_{k t} \\
I_{k t} & =I_{k t}^{+}-I_{k t}^{-}
\end{aligned}
$$

2. Storage constraint: The total number of products that can be ordered cannot exceed a particular capacity of the inventory space.

$$
\begin{aligned}
y_{k t} \leq & M_{k} Z_{k t} \\
& I_{k t} \leq M_{K}
\end{aligned}
$$

\subsubsection{Non-negativity constraint}

$$
Y_{k t}, I_{k t}^{+}, I_{k t}^{-}, A_{K}^{\prime}, A_{K}^{\prime \prime}, d_{i}^{+}, d_{i}^{-} \geq 0
$$

\subsubsection{Binary variable constraint}

$$
Z_{k t}=0,1
$$

\subsection{Model Summary}

As adapted from [4]:

Minimize $\mathrm{Z}=W_{1} d_{1}^{+}+W_{2} d_{2}^{-}+W_{3} d_{3}^{-}+W_{4} d_{4}^{+}$

\section{Subject to:}

$\sum_{k=1}^{m} \sum_{t=1}^{T}\left\{\left(C_{k} Y_{k t}+Z_{k t} S_{k t}\right)+h_{k}\left(\frac{I_{k t}^{+}+I_{k, t-1}^{+}}{2}\right)+\pi_{k}\left(\frac{I_{k t}^{-}+I_{k, t-1}^{-}}{2}\right)\right\}+d_{1}^{-}-d_{1}^{+}=C_{t}^{0}$

$\left[1-\left(\frac{I_{k t}^{-}}{\sum_{k}^{m} D_{k t}}\right)\right]+d_{2}^{-}-d_{2}^{+}=L_{k t}$

$$
\begin{aligned}
& A_{K}^{\prime}-A_{K}^{\prime \prime}+d_{4}^{-}-d_{4}^{+}=A_{k} \\
& I_{k t}=I_{k, t-1}+Y_{k t}-\sum_{k}^{m} D_{k t}(2.21)
\end{aligned}
$$

$\sum_{k=1}^{m} \sum_{t=1}^{T}\left\{\frac{C_{k} D_{k t}}{\sum_{k=1}^{m} C_{k}\left[\frac{I_{k 0}^{+}+I_{k T}^{+}}{2}\right]}\right\}+d_{3}^{-}-d_{3}^{+}=\operatorname{Tr}$ 
$I_{k t}=I_{k t}^{+}-I_{k t}^{-}(2.22)$

$y_{k t} \leq M_{k} z_{k t}(2.23)$

$I_{k t} \leq M_{k}$

$Y_{k t}, I_{k t}^{+}, I_{k t}^{-}, A_{K}^{\prime}, A_{K}^{\prime \prime}, d_{1}^{+}, d_{1}^{-} \geq 0$

$Z_{k t}=0,1$

\subsection{Solving the Problem using Lingo 17.0 and Tora 1.0}

Lingo 17.0 and Tora 1.0 software packages were employed to solve the model developed. This was thereafter programmed on the selected software packages using their respective programming commands for further analysis and comparison.

\section{Results And Discussion \\ Ranking of goals}

The non-pre-emptive goal program requires the ranking and weighing of predefined goals. These weights are subject to the decision maker's preference which is based on relative importance.

The goals, their respective ranks (according to interaction with the decision maker and further observations) and their calculated weights are presented in Table 1. This indicates that the establishment was most concerned about maximising the inventory service level. Maintaining inventory at minimum cost, having a maximum turnover and minimum lead time were also noted to be highly essential, but of secondary importance to service level.

Table 1: Ranking of Goals and their Respective Weights

\begin{tabular}{|l|l|c|c|}
\hline Goal & Description & Rank & Weight $\left(\frac{\text { rank }}{\text { totalrank }}\right)$ \\
\hline 1 & Cost minimisation & 3 & 0.3 \\
\hline 2 & $\begin{array}{l}\text { Service level } \\
\text { Maximisation }\end{array}$ & 4 & 0.4 \\
\hline 3 & $\begin{array}{l}\text { Turnover ratio } \\
\text { maximisation }\end{array}$ & 2 & 0.2 \\
\hline 4 & $\begin{array}{l}\text { Lead time } \\
\text { minimisation }\end{array}$ & 1 & 0.1 \\
\hline
\end{tabular}

\section{Model Summary}

The summary of the model for flour collated from the above objectives and constraints is presented below, while those for the other 17 raw materials take the same form except for their different values. It should be noted that $\mathrm{U}$ represents demand in the resulting models.

! FLOUR;

$\mathrm{MIN}=0.3 * \mathrm{D} 1 \mathrm{P}+0.4 * \mathrm{D} 2 \mathrm{~N}+0.2 * \mathrm{D} 3 \mathrm{~N}+0.1 * \mathrm{D} 4 \mathrm{P}$

!SUBJECT TO;

!INVENTORY COST;

$\left(\left(C^{*} \mathrm{Y}\right)+\left(\mathrm{Z}^{*} \mathrm{~S}\right)\right)+\mathrm{H}^{*}((\mathrm{I}+\mathrm{IPR}) / 2)+\mathrm{D} 1 \mathrm{~N}-\mathrm{D} 1 \mathrm{P}=1120000$

!SERVICE LEVEL;

$(1-(\mathrm{B} / \mathrm{U}))+\mathrm{D} 2 \mathrm{~N}-\mathrm{D} 2 \mathrm{P}=0.85$;

!INVENTORY TURNOVER RATIO;

$\left(\left(\mathrm{C}^{*} \mathrm{U}\right)\right) /\left(\mathrm{C}^{*}((\mathrm{I}+\mathrm{IPR}) / 2)\right)+\mathrm{D} 3 \mathrm{~N}-\mathrm{D} 3 \mathrm{P}=1$;

!DELIVERY LEAD TIME; 
$\mathrm{A}-\mathrm{APR}+\mathrm{D} 4 \mathrm{~N}-\mathrm{D} 4 \mathrm{P}=2$;

!MATERIAL BALANCE CONTRAINTS;

$\mathrm{INV}=\mathrm{INVPR}+\mathrm{Y}-\mathrm{U}$;

$\mathrm{INV}=(\mathrm{I}-\mathrm{B})$;

$$
\begin{aligned}
& \mathrm{Y}<=100 * \mathrm{Z} ; \\
& \mathrm{INV}<=100 ; \\
& ! \mathrm{DATA} ; \\
& \mathrm{U}=100 ; \\
& \mathrm{C}=11200 ; \\
& \mathrm{S}=3 ; \\
& \mathrm{H}=15 ; \\
& \mathrm{INVPR}=0 ; \\
& \mathrm{IPR}=0 ; \\
& \mathrm{APR}=0 ;
\end{aligned}
$$

!STORAGE CONSTRAINT;

!NON-NEGATIVITY CONSTRAINTS;

$\mathrm{Y}>=0$;

$\mathrm{I}>=0$

$\mathrm{B}>=0$;

$\mathrm{A}>=0$;

DIP $>=0$;

INV $>=0$;

@BIN $(Z)$;

!INTEGER CONSTRAINT;

@ GIN(Y);

@GIN(I);

$@ \operatorname{GIN}(B)$;

$@ \mathrm{GIN}(\mathrm{A})$;

@GIN(INV);

@GIN(D1P);

@GIN(D2N);

$@ \mathrm{GIN}(\mathrm{D} 3 \mathrm{~N})$;

@GIN(D4P);

Solving the problem using Lingo 17.0 and Tora 1.0

The results obtained for flour are presented below, while the results obtained for the remaining raw materials are summarised below.

\section{Lingo Result for Flour}

Local optimal solution found.

Objective value:

Objective bound:

1.200000

Infeasibilities:

1.200000

Extended solver steps:

0.000000

Total solver iterations:

Elapsed runtime seconds: 
Total variables:

Nonlinear variables:

15

Integer variables:

Total constraints:

Nonlinear constraints:

15

Total non zeros:

Nonlinear non zeros:

\begin{tabular}{cc} 
Variable & Value \\
D1P & 4.000000 \\
D2N & 0.000000 \\
D3N & 0.000000 \\
D4P & 0.000000 \\
C & 11200.00 \\
Y & 100.0000 \\
Z & 1.000000 \\
S & 3.000000 \\
H & 15.00000 \\
I & 0.000000 \\
IPR & 0.000000 \\
D1N & 1.000000 \\
B & 0.000000 \\
U & 100.0000 \\
D2P & 0.1500000 \\
D3P & $0.2248176 \mathrm{E}+09$ \\
A & 0.000000 \\
APR & 0.000000 \\
D4N & 2.000000 \\
INV & 0.000000 \\
INVPR & 0.000000 \\
DIP & 0.000000 \\
\multicolumn{3}{c}{} \\
Row & Slack or Surplus \\
1 & 1.200000 \\
2 & 0.000000 \\
3 & 0.000000 \\
4 & 0.000000 \\
5 & 0.000000 \\
6 & 0.000000 \\
7 & 0.000000 \\
8 & 0.000000 \\
9 & 100.0000 \\
10 & 0.000000 \\
11 & 0.000000 \\
12 & 0.000000 \\
13 & 0.000000 \\
14 & 0.000000 \\
15 & 0.000000 \\
16 & 0.000000 \\
D
\end{tabular}




$\begin{array}{ll}17 & 100.0000 \\ 18 & 0.000000 \\ 19 & 0.000000 \\ 20 & 0.000000 \\ 21 & 0.000000 \\ 22 & 0.000000\end{array}$

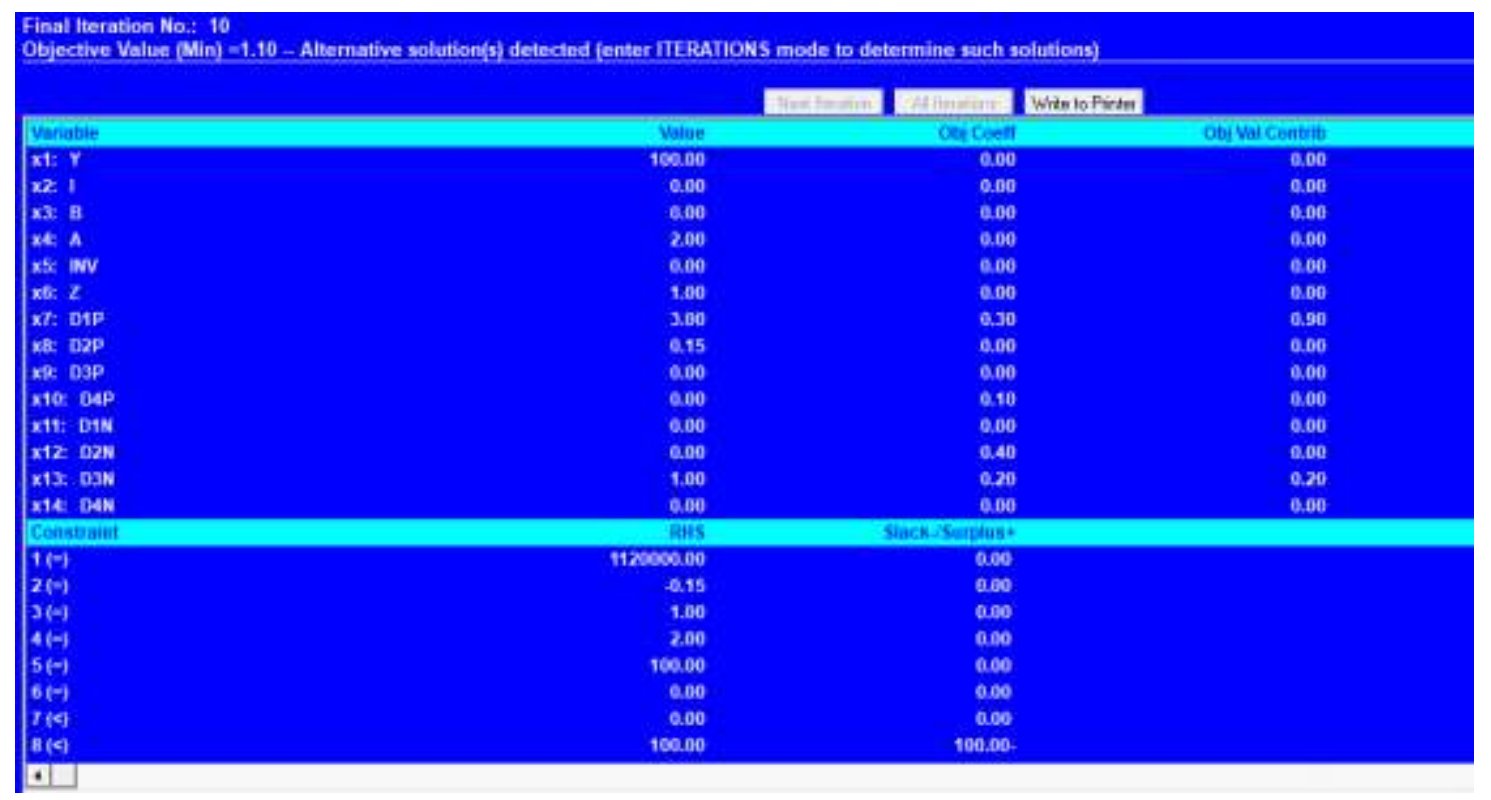

Figure 1: Tora Result for Flour

All the outcomes obtained from Lingo and Tora software packages were the same for all the raw materials. A uniform service level of $100 \%$ was obtained from both software packages for all materials, which means a $15 \%$ increase was attained. This will eliminate unnecessary waiting time in-between production, as production needs will be promptly met. The turnover ratio turned out to be greater than 1 for all the materials at a negligible increase of $<0.0001 \%$ in the varying total inventory cost of the raw materials (as presented in Table 2). The implication of the high turnover is that ordering at the optimised order quantity values gotten for each raw material will lead to effective and efficient use of raw materials in production which means reduced cost of holding. As shown in Table 2, the lead time duration is zero days ( $<24$ hours) for each material. This means that it can take hours for the material to be delivered to the inventory, but must be less than a day for the system to be optimised. For raw materials like coconut where the storekeeper goes to the supplier to get it, the product is obtained immediately it is ordered. In addition, materials such as flour, sugar, butter e.t.c are ordered and supplied within the same day under a span of 1-23 hours, since the suppliers are in close proximity to the establishment and orders are delivered the same day. This allows materials to be readily available for production processes and deters waiting time for materials.

Table 2: Summary of results for total inventory cost, order quantity and delivery lead time.

\begin{tabular}{|c|c|c|c|c|}
\hline S/n (k) & Raw Materials & $\begin{array}{l}\text { Target total } \\
\text { inventory cost } \\
(\boldsymbol{N})\end{array}$ & $\begin{array}{l}\text { Order } \\
\text { Quantity }\end{array}$ & $\begin{array}{l}\text { Lead-time } \\
\text { (hours) }\end{array}$ \\
\hline 1 & Flour & 1120003.0 & 100 & 0 \\
\hline 2 & Sugar & 220503.0 & 15 & 0 \\
\hline 3 & Salt & 7403.0 & 2 & 0 \\
\hline 4 & Butter & 112503.0 & 15 & 0 \\
\hline 5 & Yeast & 48003.0 & 4 & 0 \\
\hline 6 & Flavour (Milk) & 21502.0 & 1 & 0 \\
\hline 7 & Flavour (Chocolate) & 10002.0 & 2 & 0 \\
\hline 8 & Preservative & 29003.0 & 1 & 0 \\
\hline
\end{tabular}




\begin{tabular}{|c|c|c|c|c|}
\hline 9 & Sorbic acid & 35002.0 & 1 & 0 \\
\hline 10 & EDC Liquid & 21502.0 & 1 & 0 \\
\hline 11 & EDC 2000 & 21502.0 & 1 & 0 \\
\hline 12 & Cocoa powder & 2002.0 & 1 & 0 \\
\hline 13 & Browning & 34002.0 & 20 & 0 \\
\hline 14 & Mixed Fruit & 13002.0 & 20 & 0 \\
\hline 15 & Softener & 4002.0 & 4 & 0 \\
\hline 16 & Nutmeg & 15009.5 & 144 & 0 \\
\hline 17 & Coconut & 28802.0 & 100 & 0 \\
\hline
\end{tabular}

\section{CONCLUSION}

A bread-producing bakery was observed and a multi objective inventory model was developed, using goal programming technique and solved, evaluated and then solved with Lingo 17.0 and Tora 2.0 software packages for comparison to select the best compromise between total inventory cost, service level, turnover ratio and delivery lead time for the 17 raw materials collected while considering storage constraint on the inventory space. The following conclusions were drawn:

1. From the inventory system studied and data collected, due to the closeness of the suppliers to the bakery, lead time will usually be less than a day (that is, $<24$ hours) except when the suppliers run out of stock. Therefore, nearness to raw material source (s) is an important factor in production inventory systems.

2. Developing a multi-criteria optimisation model using goal programming approach- minimising inventory cost will eliminate non-value adding (or unnecessary) inventory costs, which will invariably reduce total cost of production, and in turn improve productivity, as well as resulting profit.

Likewise, minimising delivery lead time will prevent delay in production and maximising inventory service level will ensure availability of raw materials for production and therefore little or no waiting time and cost due to shortage.

In addition, maximising inventory turnover ratio will ascertain freshness of raw materials (that is, no wastages, expired materials or losses) and so; reduction in holding cost, thereby reducing total inventory cost.

3. Having solved the model using two different optimisation software packages (Lingo 17.0 and Tora 1.0), asides obtaining the same values from them, the best compromise solutions (service level of $100 \%$, turnover ratio $>1$ at a negligible increase of $<0.0001 \%$ in total inventory cost and available lead time of $<24$ hours for all the materials) were obtained.

\section{References}

1. Ahmadi, A., Mousazadeh, M., Torabi, S. A., and Pishvaee, M. S. 2018. OR Applications in Pharmaceutical Supply Chain Management. Operations Research Applications in Health Care Management. 461-491.

2. Alaswad, S., and Xiang, Y. 2017. A review on condition-based maintenance optimization models for stochastically deteriorating system. Reliability Engineering \& System Safety. 157: 54-63.

3. Atluri, V., Dietz, M. and Henke, N. (2017). Competing in a World of Sectors without Borders. McKinsey Quarterly, 54, 1-14.

4. Baykasoglu, A., Subulan, K., Taşan, A. S., Dudaklı, N., Turan, M., Çelik, E., and Ulker, O. 2019. Development of a Web-Based Decision Support System for Strategic and Tactical Sustainable Fleet Management Problems in Intermodal Transportation Networks. In Lean and Green Supply Chain Management. Cham: Springer. 189-230.

5. Brauer, D. C and Naadimuth, G. 1992. A goal programming model for aggregate inventory and distribution planning. Mathematical and Computer Modelling. 16.3: 81-90.

6. Ehrgott, M. et. al. 2013. Environmental development of Emerging Economy Suppliers:Antecedents and Outcomes. Journal of Business Logistics. 34.2:131-147. 
7. Ertogral, K., \& Ozturk, F. S. 2019. An integrated production scheduling and workforce capacity planning model for the maintenance and repair operations in airline industry. Computers \& Industrial Engineering. 127:832-840.

8. Hansman, F. 1962. Operations research in Production and Inventory Control. USA: John Wiley and sons. 8

9. Ivanov, D., Tsipoulanidis, A., and Schonberger, J. 2019. Operations and Supply Chain Strategy. Global Supply Chain and Operations Management: A Decision-Oriented Introduction to the Creation of Value. 2nd Ed.Switzerland: Springer. 81-110.

10. Jimoh, R., Oyewobi, L., Isa, R., and Waziri, I. 2019. Total quality management practices and organizational performance: the mediating roles of strategies for continuous improvement. International Journal of Construction Management. 19.2: 162-177.

11. Mastrocinque, E. et. al. 2013. A multi-objective Optimization for Supply Chain Network using the Bees Algorithm. International Journal of Engineering Business Management. 5.1:1-11.

12. Means, G. 2017. The modern corporation and private property. Routledge.

13. Mohamad, S. et. al. 2016, A Study on Relationship between Inventory Management and Company Performance: A case study of textile chain store, Journal of advanced management science, 4.4: 1-6.

14. Moosivand, A., RajabzadehGhatari, A., and Rasekh, H. R. 2019. Supply Chain Challenges in Pharmaceutical Manufacturing Companies: Using Qualitative System Dynamics Methodology. Iranian Journal of Pharmaceutical Research.

15. Noe, R. A.,Hollenbeck, J. R., Gerhart, B., and Wright, P. M. 2017. Human resource management: Gaining a competitive advantage. New York, NY: McGraw-Hill Education.

16. Omrani, H., Valipour, M. and Emrouznejad, A. 2018. Using weighted goal programming model for planning regional sustainable development to optimal workforce allocation: an application for provinces of Iran. Social Indicators Research. 1-29.

17. Osman, M. S., Emam, O. E., and El Sayed, M. A. 2018. Multi-level Multi-objective Quadratic Fractional Programming Problem with Fuzzy Parameters: A FGP Approach. 5.3: 1-19.

18. Pillai, R. 2010. Inventory Management Performance in Machine Tool SMEs: What factors do influence them? Journal of Industrial Engineering and Management. 3.3:542-560.

19. Punt, A. E., Butterworth, D. S., de Moor, C. L., De Oliveira, J. A., and Haddon, M. 2016. Management strategy evaluation: best practices. Fish and Fisheries. 17.2: 303-33.

20. Sekeroglu, G. and Altan, M. 2014. The Relationship between Inventory Management and Profitability: A Comparative Research on Turkish Firms Operated in Weaving Industry, Eatables Industry, Wholesale and Retail Industry. World Academy of Science, Engineering and Technology International Journal of Mechanical and Industrial Engineering. 8.6:1698-1703.

21. Sharma, J. K. 2009. Operations Research: Theory and Applications. 4th ed. New Delhi: Macmillan Publishers, India.

22. Taha, H.A. 2007. Goal programming. Operations Research: An introduction, $8^{\text {th }}$ Ed. University of Arkansas, Fayetteville. 333-341.

23. Tietenberg, T. E and Lewis L.B. 2016.Environmental problems and economic efficiency .Environmental\& Natural Resource Economics.10th Ed. New York: Routledge. 18-19.

24. Venkat, A., Miklos, D., and Nicolaus, H. 2017. Competing in a world of sectors without borders. Mckinsley Quarterly. 2-5

25. Wang, G., Gunasekaran, A., Ngai, E. W., \& Papadopoulos, T. 2016. Big data analytics in logistics and supply chain management: Certain investigations for research and applications. International Journal of Production Economics. 176: 98-110.

26. Yue, D., Pandya, S., and You, F. 2016. Integrating hybrid life cycle assessment with multi-objective optimization: a modelling framework. Environmental science and technology, 50.3:1501-1509 